\title{
CAPACITAÇÃO DE JOVENS PARA O PRIMEIRO EMPREGO
}

\author{
Jairo Leonardi de Aguiar'; \\ Jaiarys Capa Bataglin²
}

\begin{abstract}
Youth unemployment is a recurring theme in Brazilian society, with different strategies being carried out to mitigate or reduce the problems arising from the difficulty of inserting young people and adolescents in the labor market. In this context, since 2010, a project has been developed at the State University of Western Paraná, Francisco Beltrão campus , PR, called "Strategic Management for the First Job", whose objective is to train young people and adolescents in public schools for inclusion in the market of work. The analysis and discussion data were obtained through unstructured interviews with the participants of the 2019 class. As a result, it was observed: (1) a greater interest in the work; (2) the importance of technical and attitudinal knowledge for work activity; (3) enhancement and intensification of university extension activities.
\end{abstract}

Keywords: unemployment; university extension; training; youth.

Resumo: O desemprego juvenil é um tema recorrente na sociedade brasileira, com diferentes estratégias sendo realizadas visando atenuar ou diminuir os problemas decorrentes da dificuldade de inserção de jovens e adolescents no mercado de trabalho. Nesse contexto, desde 2010, é desenvolvido um projeto na Universidade Estadual do Oeste do Paraná, campus Francisco Beltrão, PR, denominado de "Gestão Estratégica para o Primeiro Emprego", cujo objetivo é capacitar jovens e adolescentes de escolas públicas para a inclusão no mercado de trabalho. Os dados de análise e discussões foram obtidos por meio de entrevistas não estruturadas junto aos participantes da turma de 2019. Como resultados, observou-se: (1) um maior interesse pelo trabalho; (2) a importância do conhecimento técnico e atitudinal para a atividade laboral; (3) valorização e a intensificação das atividades de extensão universitária.

Palavras-chave: desemprego; extensão universitária; capacitação; juventude.

\section{INTRODUÇÃO}

\footnotetext{
${ }^{1}$ Graduação em Administração - Universidade Estadual do Oeste do Paraná (Unioeste) Francisco Beltrão - Brasil. Correo electrónico: jairoleonardideaguiar@gmail.com

${ }^{2}$ Graduação em Administração - Universidade Estadual do Oeste do Paraná (Unioeste) Francisco Beltrão - Brasil.

Correo electrónico: jaiarys@gmail.com
} 
O desemprego juvenil é um problema social recorrente na sociedade brasileira, agravando-se ainda mais em momentos de crise econômica. A Organização Mundial do Trabalho (OIT, 2004), já chamava a atenção para a desocupação de jovens no Brasil, entre 15 e 24 anos, historicamente maior que a desocupação total e com os altos índices de informalidade e desemprego (OIT, 2004). Em 2019, segundo o Instituto Brasileiro de Geografia e Estatística (IBGE), a taxa de desemprego entre a população de 18 a 24 anos superou o dobro da média geral, representando aproximadamente 4 milhões de jovens, numa população total de 12,7 milhões de desempregados. A desocupação é ainda mais alta na população de faixa etária entre 14 e 17 anos, chegando a 42,2\% do total de desocupados (IBGE, 2019).

No cenário atual, de persistente crise econômica, é usual que jovens procurem desde cedo a uma vaga de estágio ou menor aprendiz, em busca de renda pessoal e/ou complementar da família. Variáveis como renda familiar, escolaridade e nível socioeconômico são determinantes para que a juventude brasileira se arrisque a enfrentar a realidade de um mercado de trabalho para o qual ainda não está preparada (Silvestre, 2015). Contribuem para isso: (1) carências da educação no Brasil, com problemas na educação formal e indefinição quanto à formação; (2) deficiências no ensino fundamental e médio, não propiciando as condições necessárias para a inserção dos jovens no mercado de trabalho; (3) distanciamento entre a formação profissional e as necessidades do mercado de trabalho; (4) e a competição acirrada entre candidatos mais qualificados e experientes (Salgado, 2014; Senai, 2016).

Tomados em conjunto, tais aspectos agravam em muito, a crônica falta de oportunidades dessa faixa etária à um trabalho decente. Quando associados à uma economia com milhões de desempregados, tornam mais escassas as possibilidades de acesso a bens, direitos e serviços, principalmente, aqueles de classe social mais baixa (Costanzi, 2009).

A fim de reduzir ou atenuar essas restrições, diversas estratégias tem sido desenvolvidas, no âmbito do poder público, setor privado e terceiro setor, incluindo também, a atuação das universidades públicas, no tocante ao planejamento e execução de cursos e ações extensionistas, uma vez que podem ser direcionados a alunos que ainda não entraram na universidade. Para Mendonça e Silva (2002), é função da universidade formular políticas e ações públicas participativas e emancipadoras, que contribuam com a solução dos graves problemas sociais da população. Serrano (2013) reafirma o papel social das universidades, ao oportunizar a formação

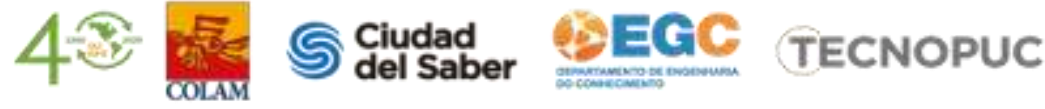


profissional e a geração e disseminação do conhecimento, por meio das atividades de ensino, pesquisa e extensão universitária. A extensão universitária, através dos projetos de intervenção direta na sociedade, possibilita oportunidades de interação entre o conhecimento empírico e científico, gerando a produção de um novo conhecimento e a mudança do status quo (Serrano, 2013).

Neste contexto, o presente estudo de caso aborda o papel da extensão universitária na preparação profissional de jovens para o mercado de trabalho. O objetivo do presente estudo, portanto, é apresentar a concepção, organização e resultados do projeto de extensão 'Gestão Estratégica para o Primeiro Emprego em Francisco Beltrão”, desenvolvido desde 2010, no âmbito da Universidade Estadual do Oeste do Paraná, campus Francisco Beltrão, em parceria institucional com a Prefeitura Municipal de Francisco Beltrão e a Agência do Trabalhador.

Esta ação de extensão tem como objetivo principal incrementar a formação e educação profissional para o primeiro emprego, de estudantes do ensino médio público da cidade de Francisco Beltrão, Paraná. Como resultados, o projeto visa despertar o interesse de jovens estudantes pelo trabalho, ressaltar a importância do conhecimento técnico e atitudinal para a atividade laboral, em qualquer atividade ou profissão, além de fortalecer a troca de experiências e parcerias institucionais e a valorização das atividades de extensão universitária junto à comunidade universitária e local.

Na próxima seção, apresenta-se a concepção, organização didática e operacional das ações desenvolvidas no âmbito da ação de extensão. Na sequência, apresenta-se o método utilizado para o desenvolvimento das atividades do projeto e os pressupostos teóricos que fundamentam a ação e discussões acerca dos seus principais resultados. E por fim, na última seção, são apresentadas as considerações finais do presente relato de caso.

\subsection{DESCRIÇÃO DO CASO: O PROJETO DE EXTENSÃO “GESTÃO ESTRATÉGICA PARA O PRIMEIRO EMPREGO EM FRANCISCO BELTRÃO”}

O projeto continuado de extensão universitária "Gestão Estratégica para o Primeiro Emprego em Francisco Beltrão" tem como principal objetivo incrementar a formação e capacitação de jovens de escolas públicas para o primeiro emprego. A ação é realizada desde 
2010, no âmbito da Universidade Estadual do Oeste do Paraná, campus Francisco Beltrão, Paraná. Cada turma de estudantes participa de aproximadamente 12 oficinas semanais, no período vespertino, com duração de aproximadamente quatro meses.

A adoção da metodologia de oficinas propicia uma abordagem participativa e inclusiva nas diversas atividades propostas. A capacitação aborda conteúdos técnicos, voltados ao mercado de trabalho, bem como conteúdos voltados ao desenvolvimento de habilidades comportamentais, ética e cidadã, tais como: (1) Processos administrativos; Empreendedorismo e mercado de trabalho; (3) Ecosocioeconomia; (4) Negociação e conflito; (5) Informática instrumental; (6) Qualidade em produtos e serviços; (7) Oratória e comunicação escrita; (8) Noções de custos e preços; (9) Mídias e dignidade humana; (10) Jovens, violência e drogas no contexto urbano; (11) Elaboração do currículo e entrevista de seleção e orientação vocacional.

As oficinas são ministradas por professores, alunos, servidores e colaboradores externos, todos voluntários, com o apoio das organizações parceiras do projeto, dentre as quais está a Prefeitura Municipal, por meio da Secretaria de Desenvolvimento Econômico e Agência do Trabalhador de Francisco Beltrão, Paraná. Até o ano de 2019, foram realizadas dezessete turmas, com novecentos e trinta e três participantes, sendo que destes, quatrocentos e trinta e quatro foram certificados (46\%), com um mínimo de $70 \%$ de frequência em cada oficina. $\mathrm{O}$ gráfico 1, demonstra o número de ingressantes e concluintes das turmas do projeto.

Gráfico 1 - Estudantes Inscritos e Concluintes

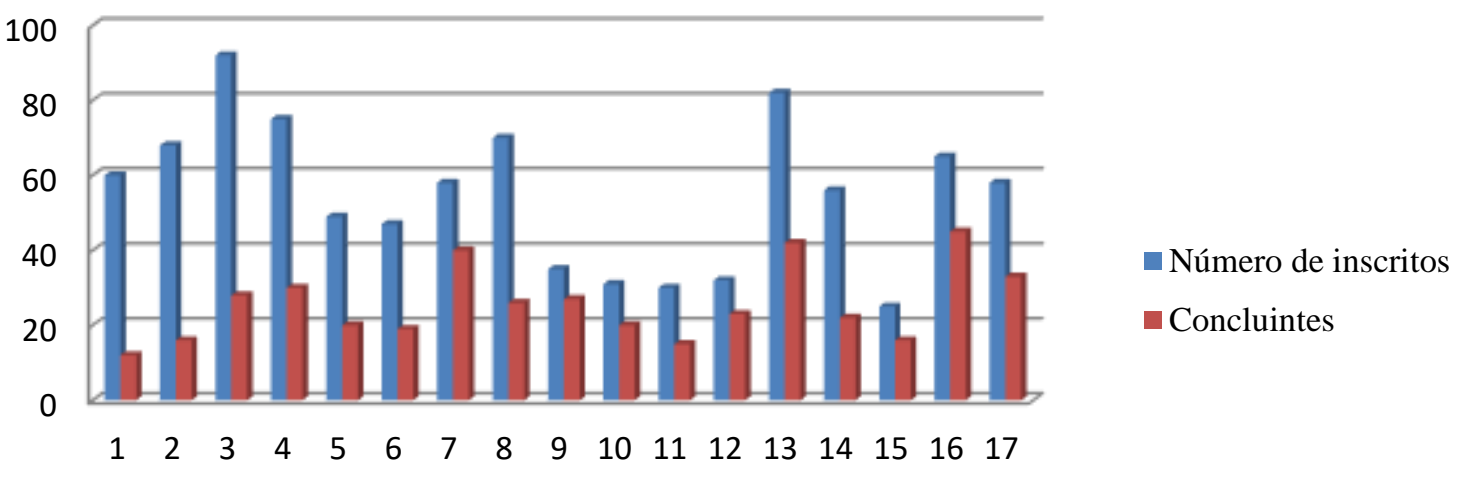

Fonte: Dados da Pesquisa (2020) 
Dentre as possíveis razões para a diferença entre o número de inscritos e concluintes, cabe citar: mudanças de cidade, trabalho e estágio, e a desmotivação e interesse em continuar no projeto, conforme relatos das direções dos colégios e dos colegas de turma, estes em interação com os acadêmicos bolsistas do projeto.

O projeto de extensão foi premiado em 2014 e 2015, com o Selo ODM - Melhores Práticas, por meio do Movimento Nacional pela Cidadania e Solidariedade - Nós Podemos Brasil. O Selo ODM busca, em âmbito nacional, reconhecer e divulgar publicamente boas práticas de instituições públicas, privadas e do terceiro setor que contribuem para o alcance dos Objetivos de Desenvolvimento do Milênio (ODM), fixados em 2000, pela Organização das Nações Unidas (ONU), e atualmente, denominados Objetivos de Desenvolvimento Sustentável (ODS).

\subsubsection{Resultados e discussão}

Para fins de resultados e discussão do presente caso, os procedimentos metodológicos adotados são de cunho qualitativo, com característica exploratório-descritiva (Creswell, 2007), visto que se buscou descrever a concepção, organização e execução da ação extensionista, além de analisar os resultados a partir da percepção dos estudantes participantes do projeto. Para isso, foram realizadas entrevistas semi estruturadas, via telefone, durante o mês de abril de 2020. Em 2019, trinta e dois estudantes concluíram a capacitação, com $70 \%$ de frequência nas oficinas. Destes, 19 estudantes foram entrevistados, sendo que os demais não foram localizados, ou não atenderam às ligações telefônicas. Todos os entrevistados eram estudantes matriculados no ensino médio dos colégios estaduais Mário de Andrade; Dr. Eduardo Virmond Suplicy; Tancredo Neves e Industrial, da cidade de Francisco Beltrão, Paraná.

De acordo com os dados da pesquisa, os entrevistados são jovens solteiros e com idade entre 16 e 17 anos, a maioria sendo do gênero feminino (63,63\%). Essa faixa etária da população brasileira apresenta, historicamente, taxas constantes de desemprego e informalidade. Em termos de desocupação, a faixa etária de 14 a 17 anos é a mais alta no Brasil, chegando a 42,2\% do total de desocupados, ou 1.064 milhão de pessoas (IBGE, 2019).

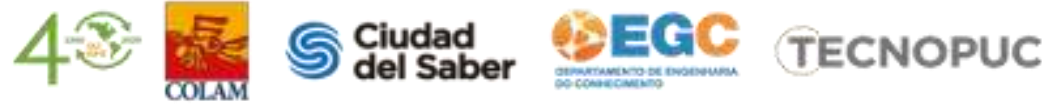


O elevado déficit de trabalho leva muitos jovens e adolescentes brasileiros a buscar o primeiro emprego em condições precárias. Neste sentido, a maioria dos entrevistados afirma sentir dificuldades para conseguir uma vaga de emprego. Dentre os problemas relatados, a falta de experiência é destacada, seguido da falta de oportunidades e de qualificação para o trabalho. Em menor grau, timidez, vergonha e nervosismo completam as dificuldades relatadas pelos estudantes.

No estudo de Botelho (2016), que buscou identificar e compreender os fatores inerentes à transição para o mercado de trabalho, entre jovens com o ensino médio, a falta de experiência profissional foi apontada como um dos principais problemas. Além disso, a baixa remuneração, desconhecimento sobre a profissão, perfil inadequado, pouco conhecimento técnico e falta de preparação para as entrevistas também foram apontadas na pesquisa. De fato, muitos jovens perdem oportunidades de emprego por não possuírem experiência prévia ou formação adequada. Para Botelho (2016) ainda existe uma certa dificuldade das empresas em aceitar um colaborador sem nenhuma experiência. Com o agravante de demandar tratamento diferenciado devido à idade e imposições legais, que podem tanto facilitar como dificultar o desenvolvimento do jovem.

Questionados sobre os motivos que os levaram a participar do projeto, a maioria respondeu buscar uma melhor qualificação para o mercado de trabalho, como indica um dos relatos. Aluno 7: "Prá fica preparado para o mercado de trabalho e independente do resultado final, arrumar um bom emprego [sic]". Outros interesses também foram citados, como por exemplo estar melhor preparado para a entrevista de emprego. Aluna 15: "Para aprender a se comportar e agir perante uma entrevista de emprego, conseguir o emprego" ou como afirma a Aluna 19: "Para aprender a se comunicar melhor com as pessoas, principalmente na hora de procurar emprego".

A respeito das contribuições do projeto, todos os entrevistados afirmaram ter contribuído de alguma forma na preparação para uma vaga de trabalho. Foram muitas as menções sobre como se comportar ou agir em uma entrevista de emprego. Aluno 1: "Na entrevista e ajudou na comunicação, pois eu tinha mera experiência sobre isso”. Outros destacaram o aprendizado na elaboração de currículos. Aluno 07: “...antes eu só preenchia os comprados, não sabia fazer um, e também em como se comportar em uma entrevista". Os

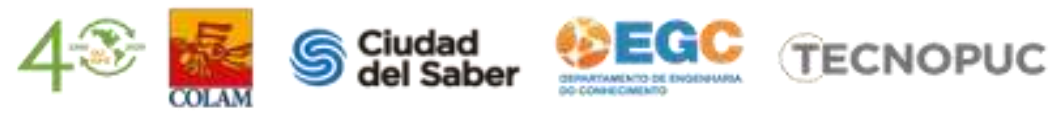


entrevistados lembraram ainda de aspectos importantes do mundo do trabalho, suas necessidades e a relação com o autodesenvolvimento, como se observa nas falas dos alunos. Aluno 03: “...tinha coisas no projeto que eu nunca tinha feito, aprendi muitas coisas novas”, Aluno 11: "Na comunicação, trabalho em grupo, desenvolvimento e de como lidar com as pessoas", e Aluno 14: ...é o que o mercado de trabalho exige. Acho que em ser mais paciente, demostrar mais segurança e responsabilidade, principalmente, no relacionamento, comunicação e aparência”.

De fato, algumas das oficinas do projeto buscavam levar o estudante a refletir em termos de comportamentos, atitudes e relacionamento interpessoal. Para Robbins (2000), desenvolver habilidades interpessoais leva ao autoconhecimento e reflexão a respeito da própria pessoa, de como se relacionar bem com outras pessoas e gerar resultados positivos dessas conexões. Como demonstram as falas a seguir: Aluno 6: "Acho que em aspectos como que eu tinha um problema de se relacionar com as pessoas, e agora consigo falar mais, me expressar mais”; Aluno 07: "Comecei a ser mais sociável. O projeto fazia atividades que faziam a gente conversar com outras pessoas que não conhecia”.

A maioria dos entrevistados concordou sobre a importância da atenção às atitudes e ao próprio comportamento. Atitude foi a palavra mais destacada, seguida de vontade e boa comunicação. As falas a seguir demonstram certa compreensão da importância dessas habilidades na busca por uma vaga de emprego. Aluno 3: "O projeto ajudou, antes eu não sabia direito o que fazer e como me comportar”. Aluno 13: “... pois eu tive que mudar tipo que roupa usar para ir na entrevista e também a roupa que devo usar no meu trabalho, que é diferente do que eu usava”.

Indagados como se sentiam tendo participado do projeto, muitos entrevistados disseram se sentir mais preparados e confiantes para as oportunidades que surgirem. Aluno 06: “...ajudou a querer ir atrás de ter potencial, de querer alguma coisa"; Aluno 18: "Sim, tinha me norteado”. De fato, sentir-se preparado e autoconfiante são atitudes pessoais importantes no competitivo mundo do trabalho. Para Salgado (2014), o sentimento de não estar preparado leva a um desestímulo em se buscar o emprego e mesmo a uma acomodação pessoal, conforme relata o Aluno 08: “O projeto tirou a barreira, aquele medo de procurar de por a cara a tapa". De fato, muitas vezes o jovem convive com a dificuldade das experiências ruins, conforme a fala 
do Aluno 15: “...daí tem um pouco de receio de buscar novamente uma vaga no mercado de trabalho". Também foi destacado a oportunidade de obter renda própria, sendo este um objetivo de grande parte dos entrevistados. Aluno 11: "Melhorou e surgiu mais oportunidades de conseguir salário". Aluno 06: "Abriu muitas portas do meu pensamento sobre ter salário". Aluno11: “Consegui um trabalho. Agora vou ter salário”.

Contudo, mesmo sentindo-se despreparados para o ingresso no mundo do trabalho, alguns estudantes relatam sentir-se cobrados a fazê-lo. A pressão muitas vezes tem origem na própria família, conforme demonstram as falas a seguir. Aluno 03: "A gente se sente inútil porque os pais ficam falando que na nossa idade já faziam tanta coisa, e que a gente não é assim”. Aluno 19: “...que não aproveita o que tem, como uma geração mal agradecida”. Em seu estudo, Silvestre (2015) demonstrou que os jovens se aventuram desde muito cedo em busca de renda complementar à familiar, mesmo sem experiência ou formação profissional adequada. Segundo seu estudo, não se trata de uma escolha pessoal, mas de uma imposição decorrente da necessidade de obter renda própria ou complementar a renda familiar (Silvestre, 2015).

Embora existam programas governamentais e de organizações da sociedade voltados à capacitação profissional de jovens e adolescentes, tais iniciativas ainda não conseguem suportar a demanda existente no país (Salgado, 2014). Dos entrevistados, a maioria (60\%) nunca frequentou cursos profissionalizantes e dos que já o fizeram, $40 \%$ foram em cursos de informática e técnicos. Neste contexto, Muhl e Mahl (2011) reafirmam o papel da extensão universitária em contribuir no atendimento das demandas da sociedade. Trata-se, na visão dos autores, de uma oportunidade prática da universidade propiciar subsídio teórico e prático através dos projetos e programas extensionistas. Já para Paula (2013), a extensão universitária fortalece o papel da universidade como instituição comprometida com a transformação social.

Conforme estudo de Silvestre (2015), a renda da maioria das famílias dos participantes do projeto no ano de 2015 situava-se entre dois e quatro salários mínimos, correspondendo às classes C2 e B1. Conforme o Critério de Classificação Econômica Brasil, a escala de categorias vai das classes de A até D, passando por B1 e B2 e C1 e C2 (ABEP, 2014), demonstrando o impacto da baixa renda familiar na decisão de buscar o primeiro emprego.

De acordo com Serrano (2013), as atividades desenvolvidas na extensão universitária devem estar em sintonia com os objetivos básicos da universidade: a educação profissional, a

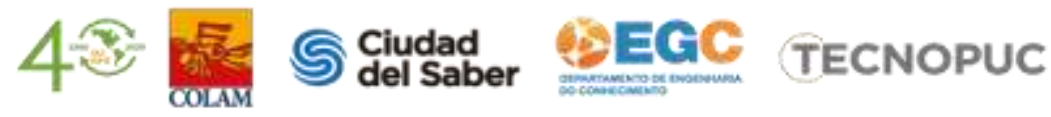


construção e a disseminação do conhecimento na comunidade. Nesse aspecto, destaca-se desdobramentos e novas iniciativas extensionistas, com foco na temática do primeiro emprego e iniciativas outras, por docentes envolvidos no presente projeto: Projeto de extensão n. 53698/2018 - Educação, orientação e cidadania financeira, no âmbito do curso de Administração da Unioeste, campus Francisco Beltrão; Projeto de extensão n. 48120/2014 Preparando para o $1^{\circ}$ emprego, no âmbito do curso de Secretariado Executivo; Projeto de extensão (em tramitação) Amarbem: Porque faz bem amar, no âmbito do curso de Ciências Econômicas. Já por iniciativa do poder público municipal, parceiro do presente projeto de extensão, foi implantado em 2020 o Programa Primeiro Emprego em Francisco Beltrão, com foco em orientações voltadas ao mercado de trabalho à estudantes de 14 a 17 anos do ensino público da cidade.

\subsubsection{Conclusão}

O objetivo do presente relato de caso foi apresentar a concepção, organização e resultados do projeto de extensão universitária "Gestão Estratégica para o Primeiro Emprego em Francisco Beltrão". O presente projeto tem como objetivo principal incrementar a formação e educação profissional para o primeiro emprego aos estudantes do ensino médio público, da cidade de Francisco Beltrão, PR. Os dados da pesquisa foram obtidos com entrevistas por telefone junto a dezenove estudantes que participaram do projeto em 2019. Os entrevistados são estudantes do ensino médio público da cidade, solteiros, a maioria do gênero feminino $(63,63 \%)$ e com idade entre 16 e 17 anos,

$\mathrm{O}$ estudo demonstrou que os estudantes sentem dificuldades em ingressar no primeiro emprego. O desemprego nessa faixa etária é alto no Brasil, com carências próprias e distintas dos demais grupos. A pouca idade, falta de experiência e de acesso à formação profissional, de acordo com a pesquisa, são aspectos limitadores na disputa por uma vaga de trabalho. Entre os problemas, a falta de experiência é a principal causa, o que já foi constatado em outras pesquisas nessa temática (Botelho, 2016; Souza, 2001; Rocha, 2008). Em menor grau, timidez, vergonha e nervosismo completam as dificuldades relatadas pelos estudantes. 
Dentre os motivos que os levaram a participar do projeto de extensão, a grande maioria afirmou estar em buscar de melhor qualificação para conseguir um emprego. Para isso, os estudantes consideram importante a capacitação técnico e atitudinal, o que contribui no acesso e desempenho da atividade laboral. De acordo com os relatos, conhecer o funcionamento de uma empresa e como se comportar nesse contexto traz confiança e amplia as perspectivas e oportunidades de trabalho, além do próprio interesse pelo trabalho.

Em termos de resultados com a participação no projeto, a maioria declarou sentir-se mais bem preparado e confiante para as oportunidades de trabalho e estágio que surgirem. De fato, sentir-se preparado e autoconfiante são atitudes pessoais importantes no competitivo mundo do trabalho e sua ausência pode levar ao desestímulo e a acomodação pessoal (Salgado, 2014).

Outra contribuição do projeto foi a oportunidade de obter renda própria, sendo este um objetivo majoritário dos entrevistados. Dos estudantes concluintes da turma em 2019, nove estavam trabalhando, seja em estágio ou emprego formal, três declararam ter optado por estudar para o vestibular e seis estudantes ainda não buscaram ou não encontraram a vaga desejada.

Nesse contexto, pode-se afirmar que o projeto contribuiu para despertar o interesse do jovem estudante pelo trabalho, além de reforçar a importância do conhecimento técnico e atitudinal junto ao seu público-alvo. Os numeros de participação no projeto são expressivos. Desde 2010, foram concluídas 17 turmas, com 933 matrículas e um total de 434 estudantes certificados. Também houve o reconhecimento externo, através da premiação com o Selo ODM - Melhores Práticas, nos anos de 2014 e 2015, feita pelo Movimento Nacional pela Cidadania e Solidariedade - Nós Podemos Brasil.

A realização do projeto reforçou o papel da extensão universitária ao provocar novas iniciativas de ações de extensão, na própria universidade. Conforme demonstrado, atualmente existem três projetos de extensão no âmbito da universidade, com foco na capacitação juvenil para o trabalho, sendo dois no campus Francisco Beltrão e outro no campus Toledo. Já por iniciativa do poder público municipal, em parceria com o Serviço Nacional de Aprendizagem Comercial (Senac), foi implantado em 2020 o Programa Primeiro Emprego em Francisco Beltrão, com foco em orientações voltadas ao mercado de trabalho. 
Por fim, cabe destacar que a execução continuada da presente ação extensionista e os seus resultados por certo não contemplam ao todo as demandas por formação e educação professional juvenil na região Sudoeste do estado do Paraná. Afinal, tratam-se de realidades permanentes e complexas e um permanente desafio para a sociedade brasileira.

\subsection{AGRADECIMENTOS}

Fundação Araucária de Apoio ao Desenvolvimento Científico e Tecnológico do Estado do Paraná.

\section{REFERÊNCIAS}

Abep (2018). Associação Brasileira de Empresas de Pesquisa. Critério de classificação econômica Brasil. Disponível em: <www.abep.org.br>. Acesso em: 07 de maio de 2020.

Botelho, D. M. R., (2016). A inserção dos jovens no mercado de trabalho: o caso dos jovens com ensino secundário. 2016. 74 f. Dissertação (Mestrado) - Curso de Gestão Estratégica de Recursos Humanos. Instituto Politécnico de Setúbal, Setúbal.

Ciep (2020). Conferencia Internacional de Educação Profissional: O conhecimento como estratégia para o desenvolvimento. Centro Senai de Excelência em Educação Profissional. Disponível em: http://www.senaipr.org.br/conferenciainternacional/uploadAddress/OIT_Livreto_portu gues[68959].pdf>. Acesso em: 14 de maio de 2020.

Costanzi, R.N. (2015). Trabalho decente e juventude no Brasil. [Brasília]: Organização Internacional do Trabalho, 2009. Disponível em: <http://www.oitbrasil.org.br/sites/default/files/topic/youth_employment/pub/trabalho_ decente_juventude_brasil_252.pdf>. Acesso em: 25 de maio de 2020.

Creswell, J.W. (2007). Projeto de pesquisa: Métodos qualitativo, quantitativo e misto. Editora: Artmed, $2^{\mathrm{a}}$ Edição. Porto Alegre.

Ibge (2019). Pesquisa Nacional por Amostra de Domicílios (PNAD). Disponível em: https://agenciadenoticias.ibge.gov.br/media/com_mediaibge/arquivos/ff2505b84b22bd cbcdbf134ea9069e28.pdf. Acesso em: 20 de maio de 2020.

Mendonça, S. G. L.; Silva, P.S. (2002). Extensão Universitária: Uma nova relação com a administração pública. Extensão Universitária: ação comunitária em universidades brasileiras. São Paulo, v. 3, p. 29-44.

Muhl, C.; Mahl, C. A. (2015) Construção das representações sociais na universidade: compreendendo o papel do docente e discente. 2011. Disponível em: 
<http://editora.unoesc.edu.br/index.php/achs/article/viewFile/571/pdf_146>. Acesso em: 06 abr. 2020.

Oit (2004). Organização Internacional do Trabalho. Desemprego juvenil no Brasil: em busca de opções à luz de algumas experiências internacionais. 2. ed. - Brasília.

Paula, J. A. de. (2013). A extensão universitária: história, conceitos e proposta. Interfaces Revista de Extensão, v.1, n. 1, p. 5-23.

Robbins, S. P. (2000). Administração, Mudanças e Perspectivas, São Paulo: Editora Saraiva.

Rocha, S. (2008). A inserção dos jovens no mercado de trabalho. Caderno CRH, Salvador, v.1, n.54, pp.533-550.

Salgado, I. C., (2015). Jovens ainda enfrentam dificuldades para entrar no mercado de trabalho. 2014. Disponível em: <http://chicoterra.com/2014/04/29/jovens-ainda-enfrentamdificuldades-para-entrar-no-mercado-de-trabalho/> . Acesso em: 14 de abril de 2015.

Serrano, R. M., (2015). Conceitos de extensão universitária: um diálogo com Paulo Freire. 2013.Disponível em: <http://xa.yimg.com/kq/groups/20876648/372422751/name/conceitos_de_extensao_u niversitaria.pdf.>. Acesso em: 05 de abril de 2020.

Silvestre, A.C., Aguiar, J. L. de., Colussi, L. T. G. (2015) Perfil Socioeconômico dos estudantes do projeto de extensão do primeiro emprego. IV Congresso Nacional de Pesquisa em Ciências Sociais Aplicadas (CONAPE). Francisco Beltrão, Pr.

Souza, N. R. M., (2019). A inserção dos jovens no mercado de trabalho. Fundação João Pinheiro, Centro de Estatística e Informações. Belo Horizonte. 